\title{
Lumpy Skin Virus; Herpesviridae Inevitable Synergism
}

Samia Ahmed Kamal ( $\square$ selkabany@yahoo.com )

Animal Health Research Institute

\section{Research Article}

Keywords: Orthopoxvirus, Capripox, lumpy skin, cattle, Negative staining, poxvirus, herpes, electron microscope, LSD, TEM

Posted Date: January 28th, 2022

DOI: https://doi.org/10.21203/rs.3.rs-1290778/v1

License: (9) (1) This work is licensed under a Creative Commons Attribution 4.0 International License. Read Full License 


\section{Abstract}

Background: Lumpy skin virus causes huge economic losses in farm animals. Herpesviridae are opportunistic and showed synergistic role but worsen disease symptoms. By using TEM \& negative staining one avoid the problematic concerns of differential diagnosis.

Materials and Methods: Cutaneous crusts collected from infected cattle, samples examined directly by the electron microscopy, then confirmed by the Conventional Polymerase Chain Reaction and partially sequenced by ORF103 gene.

Results: This study reveals that the source of infection was not related to the vaccines. It turns out to be a natural infection by Lumpy skin disease virus isolate Evros / GR/15 and 99\% identity. A comparison of the gene sequence of the vaccine against the virus showed significant divergence between them. Negative staining electron microscopy reveals Lumpy skin disease virus \& Herpes viruses in different sizes and forms. Herpesviridae members were contaminating LSD lesions as TEM reveals the presence of different herpes types.

Conclusions: LSD virus of cattle showed virulent nature in natural outbreak. However, the herpes viruses invade infected tissues and propagate inside cells of lumps that revealed its opportunistic behavior. Consequently; Antivirals against Herpesviridae would theoretically relief lumpy skin disease symptoms and help in control efforts.

\section{Background}

Lumpy Skin Disease (LSD) is the pox disease of cattle, is the most threat to cattle industry. Lumpy Skin Disease Virus (LSDV) belongs to genus Capripoxvirus [Poxviridae], which as poxvirus have linear double-stranded DNA genome, enveloped, large, epithelia-tropic. This virus has caused multiple epidemics in different places in Egypt, throughout the year and is still present. Lumpy Skin Disease was first recognized in Zambia in 1929. However, the first recorded infections in Egypt were in 1988, in Europe in Cyprus in 2014, Greece in 2015, and Balkan countries in 2016 [1-7]. The poxvirus contains A+T-rich genome, more than 100 polypeptides, arranged in core, lateral body, membrane, and envelope. The membranes are lipoprotein bilayer which surrounds; a core and lateral bodies. The outer surface is studded with randomly arranged surface tubule elements. The intracellular mature virion has the nucleoprotein core and the lateral bodies enclosed by inner membrane, and outer membranes [1]. However, the enveloped virion is fully matured virus and covered by smooth capsule formed mainly of lipoprotein and glycoproteins. The enveloped virus contains a distinct glycoprotein; these virus antigens present in the envelope are capable of eliciting immunity [3]. Pathogenesis of LSDV in cattle; primarily the LSD virus propagated inside the epithelium of the skin prickle cell layer causing hyperplasia which leads to hyperkeratosis and parakeratosis. The endothelial cells of blood vessels infected by the virus suffer necrosis which leads to thrombus formation with subsequent infarction. LSDV has the affinity to produce pox lesions in various internal organs, skin and the mucous membranes. Pathogenesis of that disease showed its destructive behaviors towards affected cells, as LSDV cause necrosis to blood vessels' endothelium and smooth muscles surrounding blood vessel' walls. Conjoint of ischemia of tissues and direct necrotic effects on affected skin cells leads to the typical pathological figure of lumps $[8,9]$.

Herpes viruses are ubiquitous in nature, which causes a wide variety of diseases. The Herpes virus mature virions are enveloped, ds-DNA genome, with specific TEM morphology. The electron microscopic studies on the morphology of herpes viruses, the negative staining method of Brenner \& Horne (1956) revealed the morphological detail which has become so characteristic of the group [10]. Epstein (1962a) has described the envelope as a triple- layered membranous structure indistinguishable from host cell membrane [11]. Epstein (1962b) showed dense core region contained DNA and type of fixation and embedding affected core morphology [12]. It could be postulated that poxviruses able to exerts their effect by the presence of the indispensable herpes virus's coinfections. [13-16].

Lumpy Skin Virus continues spreading from Eastern Europe to Asia. However, LSD was first reported in Asia and the Pacific region in 2019 in northwest China, Bangladesh and India. During 2020, LSD has continued its spread across continental Asia; south and south East Asia confirming outbreaks. LSD recorded in Bangladesh, India, Nepal and Sri Lanka in 2019. In South Asia, the disease spread through Northeastern Thailand to China, Chinese Taipei, Hong Kong, Bhutan, Myanmar and Vietnam [17-21].

\section{Materials And Methods}

\section{Live Attenuated Vaccine-Vaccine Batch 18024}

Live attenuated vaccine (for cattle and buffalo's poxviruses), produced by (VSVRI) of Egypt used in the present work, for comparing it by the circulating LSDV in Egypt.

\section{Samples Preparation}

Tissue specimens collected from infected cattle and obtained by detaching skin crusts and kept in sterile tubes and kept at $4^{\circ} \mathrm{C}$ until the specific procedures [22].

\section{Electron Microscopic Examinations}

\section{Transmission EM}

The procedures were performed at Cairo University, faculty of agriculture. The Direct Electron Microscope \& Negative Staining is a rapid method.

\section{Test procedures}


Direct Electron Microscopy (DEM): The original biological specimens were re-suspended in $50 \mu \mathrm{L}$ of Phosphate-Buffered Saline (PBS) pH 7.2. One drop of the suspension was put on EM grid and submitted to negative staining technique with $2 \%$ Potassium Phosphotungstate (PTK) pH 6.4. The grids were examined and the viruses were documented in a Philips EM400-T electron microscope operating in $80 \mathrm{kV}$. All samples examined by NS-DEM, and the procedures were performed according to $[10,23]$.

\section{Polymerase Chain Reaction (PCR) Assays}

The conventional method and partial genome sequencing for ORF103 gene: Performed in reference laboratory [AHRI, Doky, Egypt].

\section{Extraction of genomic DNA}

The supernatant of prepared scab's samples was collected for viral DNA extraction using a Viral DNA Extraction Kit, according to manufacturer instructions and then used as a template in PCR.

\section{PCR amplification}

The Open Reading Frames (ORFs) of the ORF 103 gene were amplified via PCR from DNA extracted from original samples. Primers: Target ORF103 gene for 570 bp-seq. [Forward 5' ATGTCTGATAAAAAATTATCTCG 3'] [Reverse 5' ATCCATACCATCGTCGATAG 3']. PCR amplification proceeded with an initial denaturation step of $94^{\circ} \mathrm{C}$ for $5 \mathrm{~min}$ followed by 35 cycles at $94^{\circ} \mathrm{C}$ for $1 \mathrm{~min}, 52^{\circ} \mathrm{C}$ for $45 \mathrm{~s}, 72^{\circ} \mathrm{C}$ for $1 \mathrm{~min}$, and a final extension of $72^{\circ} \mathrm{C}$ for 10 min. Amplicons were visualized via electrophoresis on a $1.0 \%$ Agarose gel and documented with a gel documentation system.

\section{Cloning and DNA sequencing}

The PCR products of the ORF 103 genes were then cloned \& Compared to the isolates of Poxviridae family in Gene-Bank database using the online Basic Local Alignment Search Tool program. Sequence identities of nucleotides between the isolated and NCBI sequences were analyzed. The nucleotide sequences deduced were assembled into a multiple sequence alignment.

\section{Results}

\section{Symptoms}

Cattle suffering Lumpy Skin Disease showed enlarged lymph nodes; skin nodules in different stages. New nodules showing subcutaneous swellings erupted beneath the old ones, bleeding from old lesions was seen as a result of animal movements. Prolonged lesions lead to emaciation (Figure 1).

\section{TEM, negative staining: Lumpy skin virus \& Herpesviridae members}

\section{1- Lumpy skin virus}

\section{Forms of LSDV referring to:}

- Extracellular Enveloped Virion (EEV) transmitted outside for disseminating the infection.

- Non-enveloped M (Mulberry) intracellular mature virion.

- Virulent Virus (VV); new form indicating virulence behavior and aggressive outbreak.

\section{The study findings:}

\section{EEV form}

The TEM- negative staining picture shows a number of viruses in poor condition with cracking marks in their viral cover. They are relatively different in size and form, $138 \mathrm{~nm}-220 \mathrm{~nm}$, but are united in their condition. Perhaps the shape of the picture is not indicative of its reality, but compared to other images came this judgment (Figures 2,3). The photos showed Herpes viruses surrounding the LSD virus and attached to its outer cover (envelope). Herpes viruses were collected in very large numbers and appeared in the adherent examination, although the test was performed on a solution, which means that the Herpes virus is well integrated with the LSD virus. The images show a large number of viruses of relatively different sizes but all are covered by the smooth viral membranes (Figure 4). The LSD viruses appear as a smooth brick shapes (Figures 5, 6).

\section{$M$ form}

The image of the virus is clear and is covered with arranged structures in the form of overlapping short tubules of about (100 nm x $160 \mathrm{~nm})$ (Figure 7). The picture shows a number of viruses partially covered by the internal viral membranes and surrounded by another incomplete membrane. Some viruses look relatively dark and surrounded by a light-colored membrane, it is surrounded by a light-colored membrane that may be composed of materials that do not absorb the dye. There is some variation in the size of viruses (111 nm-221 nm) (Figure 8). The picture shows a number of viruses partially covered by the internal viral membranes and surrounded by another incomplete membrane. The picture shows well the internal structure of the virus and the ex-act cover consisting of short, intermittent tubes revolving around a center axis; it is surrounded by a thick, incomplete membrane, as if the virus is in the shape of a horseshoe (Figure 9). 
W form

A virion showing a component inside the virus appeared cone-shaped. Half of the virus is exposed and the back is given as a funnel. The DNA molecule appears surrounded by a fine component that preserves it from the external environment. The virion covered by a smooth membrane which may be the incomplete envelope. This LSD virus virion is large, and about $(230 \mathrm{~nm} \times 231 \mathrm{~nm})$ (Figures 10, 11). The image shows a set of interconnected viruses. The virus takes different pleomorphic forms. The membranes that retain viral components take an intermediate position among the enveloped and non-enveloped LSD viruses. The image shows herpes viruses interlaced with LSD viruses. The image gives the impression that viruses are very active (Figures 12,13 ). This virus is surrounded by a transparent membrane showing the components it contains. This form of LSDV indicates that it is highly virulent; it takes off its covers in preparation for new host.

The TEM, negative staining image shows the herpes virus connected to a thin line extending towards the other virus and both viruses in a functional state (Figure 14). This virus is surrounded by a transparent membrane showing the components it contains. The composition inside the virus appears to be quite similar to the nutshells. Inside the figure shows a dark color while the frame that draws the shape is light colored. This form of LSDV indicates that it is very virulent; it takes off its covers in preparation for new host $[15,16]$.

\section{Herpesviridae}

NS-DEM analysis

The TEM, negative staining images shows herpes virus as a tennis ball (core) in the middle of a halo (envelope). This is because the membranes surrounding it break easily to give this distinctive shape of $23 \mathrm{~nm} \times 77 \mathrm{~nm}$ (Figures 17-21). The picture shows naked and enveloped herpes virus of average sizes of 78.5 $\mathrm{nm}-81 \mathrm{~nm}$. The core of enveloped herpes virus measure about $33 \mathrm{~nm}$ (Figure 22). The image shows the enveloped Herpes virus, but the internal content appears because it is a weak membrane and breaks easily. Herpes viruses appear to be in a highly functional and in active state (Figure 23). The picture shows naked herpes viruses of average sizes about $57 \mathrm{~nm}-72 \mathrm{~nm}$. The image shows herpes virus in large numbers and active (Figures 24,25$)$.

\section{Results of conventional Polymerase Chain Reaction (PCR):}

Samples were positive for LSD virus by conventional PCR and genetically characterized as Lumpy skin disease virus isolate Evros/GR/15 by partial sequence with $99 \%$ identity (Picture 1, 2).

\section{LSDV sequence:}

[.......CTAATCCTTCAGCTACCACGTTTATTAACTTTTTTTTTGATTGTGAAATATTTTTGTTTCGTCTACCAGCATTTACTGATTCTATTCCTAACAAGTCTTGATTTATTTC,

\section{Vaccine sequence:}

Vaccine sample was positive for Capri-pox virus by conventional PCR and genetically characterized as Sheep pox virus strain Jaipur and Sheep pox virus Romanian Fanner by partial sequence with $99 \%$ identity targeting ORF103 gene (Picture 3).

\section{Sequence: live attenuated vaccine (sheep pox virus):}

[.........TTGCTCACATTAGTGGAGAACAAGCATCTCAAAAATCAAATCTTACTCCAGAGGATAATACTACTAATAATATAGATGAAAATGAAGTAAAAGCTGGCAATGTGAAA

\section{Discussion}

OIE, 2022: Stated that "LSD is currently endemic in most of Africa, parts of the Middle East and Turkey. Since 2015, the disease has spread to most of the Balkan countries, the Caucasus and the Russian Federation, where the disease continues to spread, making the risk of an imminent incursion into other unaffected countries very high. Since 2019, several outbreaks of LSD have been reported by Members in Asia (Bangladesh, India, China, Chinese Taipei, Vietnam, Bhutan, Hong Kong (SAR-RPC), Nepal, Sri Lanka, Myanmar, Thailand)" [20].

My findings reveal that LSDV is highly contagious as a result of intracellular proliferation inside the most susceptible host (young cattle). The persistence of the virus so far in the affected areas indicates a decrease in the immunity of the entire herd. And also indicates that viruses (causative agents) are present in the environment of animals in considerable amount. The enveloped and the non-enveloped LSD viruses were in large numbers and both are in active state. The presence of enveloped viruses indicates the virus is ready to infect new hosts and persist in the region. These observations indicate that virus propagates inside cattle tissues which have poor immunity. Moreover, the presence of large number of viruses indicates that the infection circulates in cattle and become endemic. Lojkic et al., (2018) report that LSD virus was isolated from a skin nodule sampled away from the vaccine injection site and passaged eight times on Madin-Darby Bovine Kidney (MDBK) cells, complete genome was determined and the obtained genome sequence (150,448 bp) was $100 \%$ identical to that of the vaccine virus [25-27]. The electron microscope findings are in accordance with Weiss (1968) who mentioned that lumpy skin disease virus consist of a complex interwoven network of strands each with an approximate and presenting an irregular surface structure. A regular arrangement of "teeth" along the margins of some particles was evident. Preparations negatively stained at pH 8.5 showed a predominance of particles with multilayered capsules. These particles did not show the thread-like surface structure but consisted of a homogeneous granular mass enveloped by a capsule. The capsule appeared to have an irregular outer membrane, a thicker central part and a distinct inner membrane [2]

It has recorded that Poxvirus outer and inner membranes are lipoprotein bilayer which surrounding the two lateral bodies and the viral core. The non-enveloped virus showed the surface short tubular arrangements, giving the mature LSD virus its textured surface (Figures 7-9). The mature virion composed of a 
nucleoprotein core and associated lateral bodies enclosed by smooth inner membranes and outer tubular lipoprotein coat (intracellular) and some virions wrapped by the envelope (extracellular) (Figures 5,6) as additional lipid bilayer that giving the poxvirus the smooth brick-shaped appearance [1,11]. Negative staining EM of the mature virion of LSD virus show viral membrane encloses a biconcave or cylindrical core that supposed containing the viral DNA genome and the organized nucleoprotein complex (Figures 10,11). Two lateral bodies present in the concave region between the core wall and inner membranes (Figure 15, 16), the nucleoprotein complex might be cylindrical, folded along the long axis (Figure 9) arranged linearly [15, 16]. A comparison of the gene sequence of the vaccine (sheep pox virus) against the LSD virus showed significant divergence between them.

LSD virus detected in multiple form and size but is genetically identical and has distinct antigenicity. LSDV impair the innate immune system, so that it is difficult to eradicate. The only way for successful control of disease is the efficient preventive measures because vaccination against showed unusual failure, as many evidences was reporting this fact. For examples, Croatia has a special experience regarding LSD in 2016, for the first-time vaccination of the entire cattle population was conducted without an index case. The presence of vaccine viral particles was detected in milk, skin nodules; blood and nasal swabs in seven from total of eight herds. The presence of virus genome was detected in five cows from 10 up to 21-day post-vaccination [27].

The virus was successfully isolated on cell culture from 10 up to 21-day post-vaccination from three animals [26]. However researchers in Jordan reported adverse reactions following vaccination, the geographical areas enrolled in their study were free of the disease and away from the outbreak governorates. Sixty-three farms, with a total of 19,539 dairy cattle animals, were included in the study. Of those, 56 farms reported adverse clinical signs after vaccination. Clinical signs were similar to those observed with natural cases of lumpy skin disease [27]. However, Boulanger et al (1996) reported that following fox vaccination campaign using vaccinia-rabies recombinant virus, they detected Orthopoxvirus in many other wild animals as squirrels, bank voles and wood mice [28]. Lumpy skin disease virus when infects the skin, disrupts the immune system, however, our findings are in accordance with Weiss (1968) who mentioned that Lumpy skin disease characterized by fever and the sudden appearance of firm circumscribed skin nodules, subcutaneous edema of the limbs and ventral parts of the body and a generalized lymphadenitis, and many characteristics in common with the vaccinia-variola subgroup. He added that during an outbreak, some animals may escape infection entirely and remain susceptible and lumpy skin disease can spread in the absence of insects and even under conditions where direct or indirect contact of infected herd and susceptible animals does not exist. In the infected animal, virus is present in the skin nodules, muscles, blood, spleen and saliva [2].

\section{Conclusions}

It could be concluded that herpes virus help Lumpy skin virus in natural infections. However, meat of infected cattle is not suitable for human consumptions.

\section{List Of Abbreviations}

DEM: Direct electron microscope. LSDV: lumpy skin disease virus. NS: negative staining. PCR: polymerase chain reaction.

\section{Declarations}

\section{Competing interest:}

I declare that "I have no conflict of interest"

\section{Contributions:}

I'm Dr. Samia Ahmed Kamal, the corresponding author; who did this research, designing it; investigate the areas, analyses the data \& collecting the literatures, recorded the results \& discussing it, writing the research \& sending it for publishing.

\section{References}

1. Fenner F (1996). Poxviruses, p. 2673-2702. In B. N. Fields, D. M. Knipe, and P. M. Howley (ed.), Fields virology. Lippincott-Raven, Philadelphia, Pa.

2. Weiss KE (1968). Lumpy skin disease. Virol. Monogr. 3, 111-131.

3. Mark R, Buller L \& Gregory JP (1991). Poxvirus Pathogenesis. Microbiological Reviews Mar. p. 80-122 Vol. 55, No. 1 0146-0749/91/010080

4. European Commission (2016). Decision (EU) No 2016/2008 of 15 November 2016 concerning animal health control measures relating to lumpy skin disease in certain Member States, Official Journal of the European Union 2016; L310:51-65.

5. House JA, Wilson TM, El Nakashly S, et al. (1990). The isolation of lumpy skin disease virus and bovine herpesvirus-4 from cattle in Egypt. J Vet Diagn Invest; 2(2):111-115 https:// doi.org/10.1177/104063879000200205 PMID: 1965577

6. Carn VM, Kitching RP (2015). An investigation of possible routes of transmission of lumpy skin disease virus (Neethling). Epidemiology and Infection 1995; 114(1):219-226. PMID: 7867740 11. Rodhain F: Insects as vectors: systematics and biology. Rev. Sci. Tech. Off. Int. Epiz.; 34 (1):83- 96.

7. Palmer EL, Martin ML (1988). Electron Microscopy in Viral Diagnosis; CRC Press Inc.: Boca Raton, FL, USA.

8. Samia Ahmed Kamal et al. (2016). Some studies on lumpy skin disease. Egypt. J. Chem. Environ. Health 2016.

9. Prozesky L, Barnard BJ (1982). A study of the pathology of lumpy skin disease in cattle. Onderstepoort Journal of Veterinary Research; 49(3):167-175. PMID: 7177597

10. Brenner S and Horne RW (1959). A negative staining method for high resolution electron microscopy of viruses. Biochim. Biophys, Acta 34,103-10. PMID: 13804200 
11. Epstein MA (1962) a. Observations on the mode of release of herpes virus from infected hella cells. J Cell Biol. 1962 Mar 1; 12(3): 589-597. PMCID: PMC2106053

12. Epstein MA (1962) b. Observations on the fine structure of mature herpes simplex virus and on the composition of its nucleoid. J. Exptl. Med. 115:1-12. DOI: 10.1084/jem.115.1.1

13. Kaplan AS (1973). The Herpesviruses. Text book. Academic Press, INC, USA.

14. Lee LF, Kieff ED, Bachenheimer SL, Roizman B, et al. (1971). Size and composition of Marek's disease virus deoxyribonucleic acid. J Virol. Mar; 7(3):289294. [PMC free article] [PubMed]

15. Tokumaru T (1963). Hypersensitivity to herpes simplex in guinea pigs. Federation of American Societies for Experimental Biology Proceeding. $22: 616$.

16. House JA, Terrance MW, Sinan EN et al. (1990). The isolation of lumpy skin disease virus and bovine herpes virus from cattle in Egypt. J Vet Diagn. Invest; $2: 111-115$

17. Arjkumpa O, Suwannaboon M, Boonrawd M et al. (2021). First emergence of lumpy skin disease in cattle in Thailand, 2021. Transboundary and Emerging Diseases, 68, 3002-3004. https://doi.org/10.1111/tbed.14246

18. Acharya KP \& Subedi D (2020). First outbreak of lumpy skin disease in Nepal. Trans-boundary and Emerging Diseases, 67 (6), 2280 - 2281 https://doi.org/10.1111/tbed.13815

19. Lu G, Xie J, Luo J, Shao R, Jia K \& Li S (2021). Lumpy skin disease outbreaks in China, since 3 August 2019.Transboundary and Emerging Diseases,68(2),216-219.https://doi.org/10.1111/tbed.13898

20. OIE (2021).Lumpy Skin Disease (LSD) OIE: Asia and the Pacific.https://rr-asia.oie.int/en/projects/lumpy-skin-disease-Isd/

21. Tran HTT, Truong AD, Dang AK, et al., (2021). Lumpy skin disease outbreaks in Vietnam, 2020. Transboundary and Emerging Diseases, 68,977-980. https://doi.org/10.1111/tbed.14022

22. Payment $P$ and Trudel M (1993). "Methods and Techniques in virology." Text book; Marcel Dekker INC., USA.

23. Hayat MA (1981). Principles and techniques of electron microscopy. Biological applications, second ed.; University Park Press, Baltimore, MD, Vol. 1.

24. Tcherepanov V, Ehlers A, Upton C (2006). Genome annotation transfer utility (GATU): rapid annotation of viral genomes using a closely related reference genome. BMC Genomics 7:150. https://doi.org/10.1186/1471-2164-7-150.

25. Lojkic I, Šimic I, Krešic N, Bedekovic T (2018). Complete Genome Sequence of a Lumpy Skin Disease Virus Strain Isolated from the Skin of a Vaccinated Animal. Genome Announc. Viruses. 6:e00482-18.https://doi.org/10.1128/genome A .00482-18.

26. Bedekovic' T, Šimic' I, Krešic' N, Lojkic' I (2017). Detection of lumpy skin disease virus in skin lesions, blood, nasal swabs and milk following preventive vaccination. Transbound Emerg Dis 65:491-496. https://doi .org/10.1111/tbed.12730.

27. Abutarbush SM, Hananeh WM, Ramadan W et al. (2016). Adverse Reactions to Field Vaccination against Lumpy Skin Disease in Jordan. Transbound Emerg Dis. 2016 Apr; 63(2):e213-9. doi: 10.1111/tbed.12257.

28. Boulanger D, Crouch A, Brochier B, et al. (1996). Serological survey for orthopoxvirus infection of wild mammals in areas where a recombinant rabies virus is used to vaccinate foxes. Vet Rec 138: $247-249$

\section{Pictures}

Pictures are available in the Supplemental Files section.

\section{Figures}

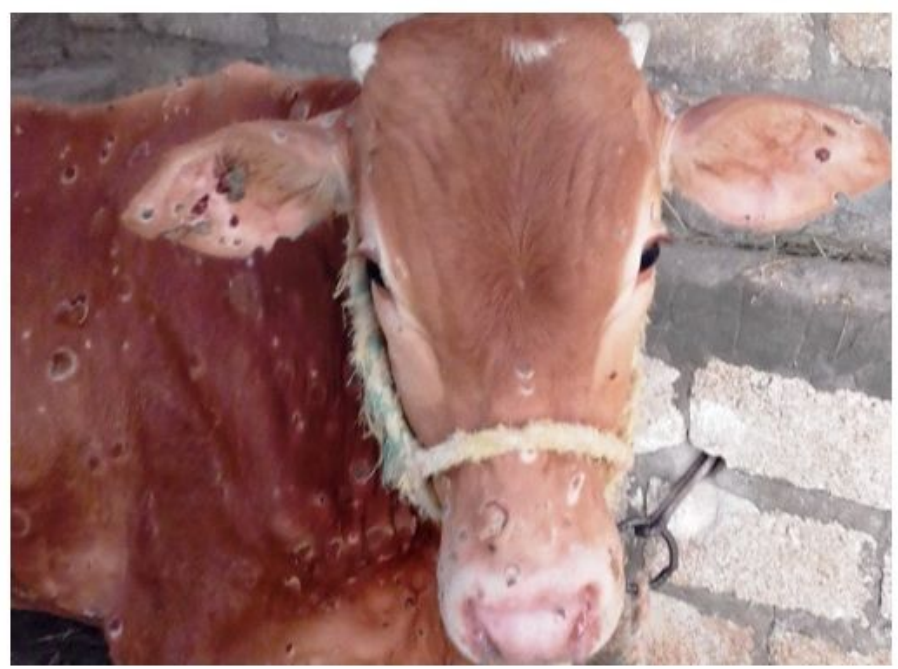

Figure 1 
Cattle suffering Lumpy Skin Disease: showed enlarged lymph nodes, the skin nodules were in different stages, some were sloughed taking a piece of ear cartilages to the ground. New nodules showing sub- cutaneous swellings erupted beneath the old ones. Some bleeding from old lesions was seen as a result of animal movements. Emaciation was observed, (sit fast) lesions were also present between different stages of skin lesions. [Fayoum Gov. August, 2018].

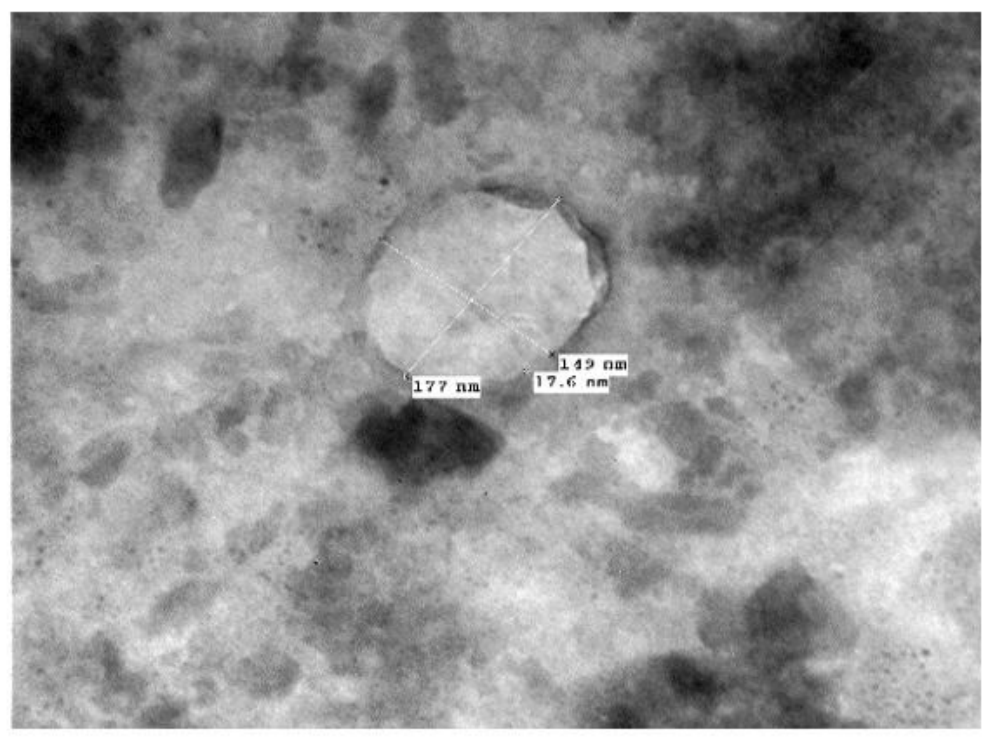

\section{Figure 2}

LSD nodules from infected Cattle: EEV form: TEM, negative staining picture shows enveloped viral particle (149 nm x $177 \mathrm{~nm})$, [NS-TEM $150000 \mathrm{X}$.

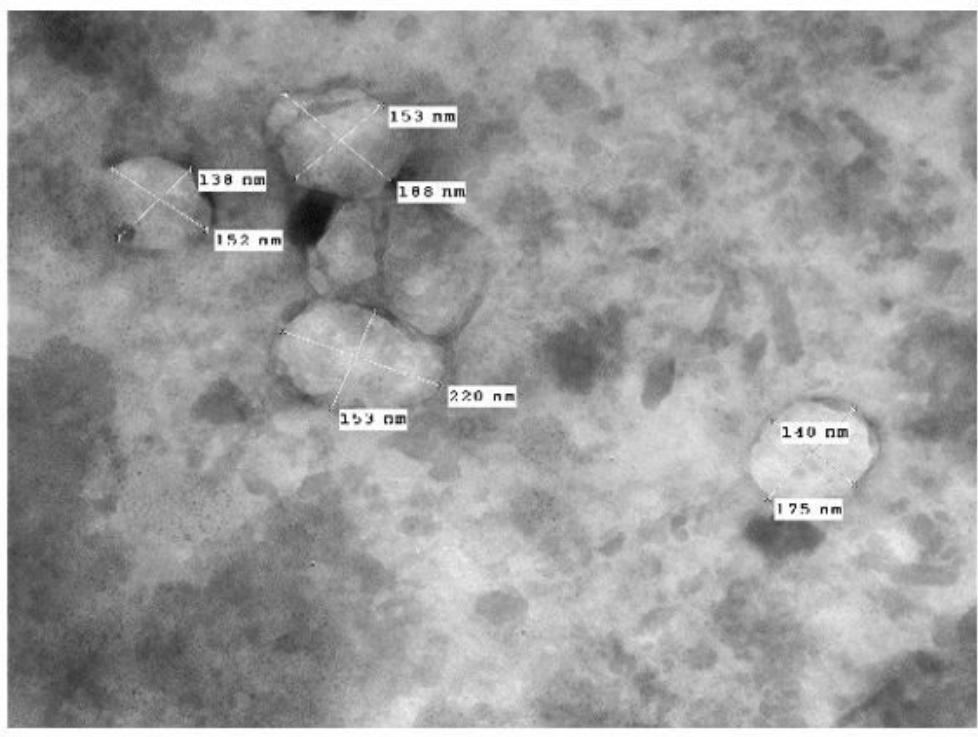

\section{Figure 3}

LSD (Cattle) EEV form, negative staining showing some viruses in poor condition with cracking marks in their viral cover [envelope]. They are relatively different in size and form, $138 \mathrm{~nm}-220 \mathrm{~nm}$. TEM 80000X. 


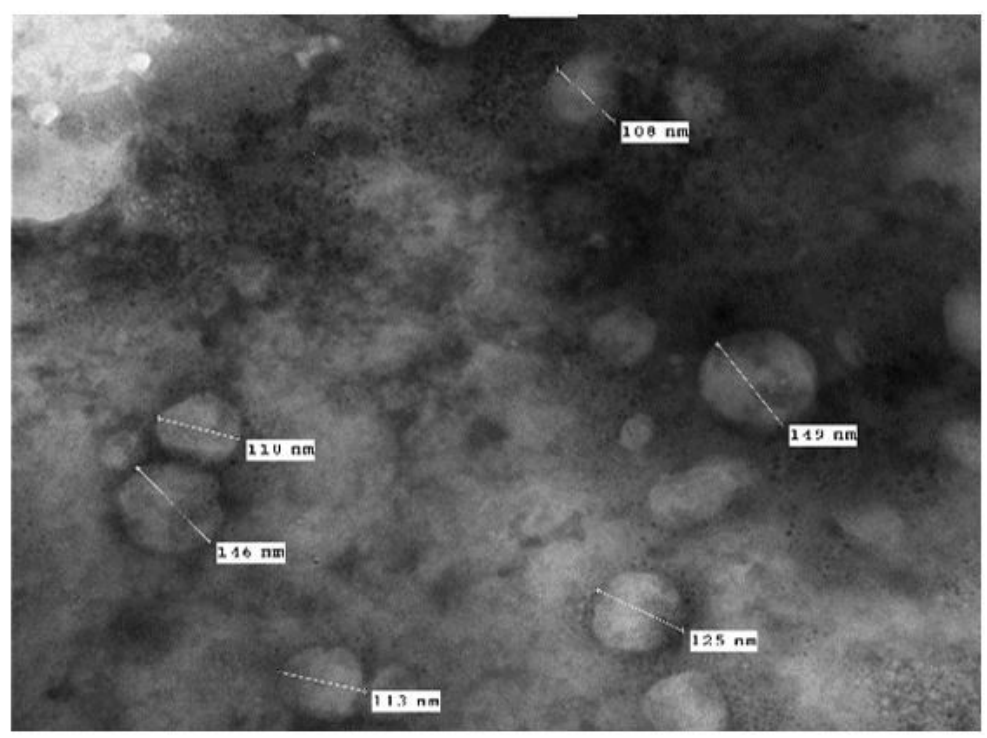

\section{Figure 4}

LSD nodules from infected Cattle: EEV form: The TEM, negative staining images show a large number of viruses of different sizes but all are covered by the smooth viral membranes [envelope] (100 nm-150 nm), [NS-DEM 80000X].

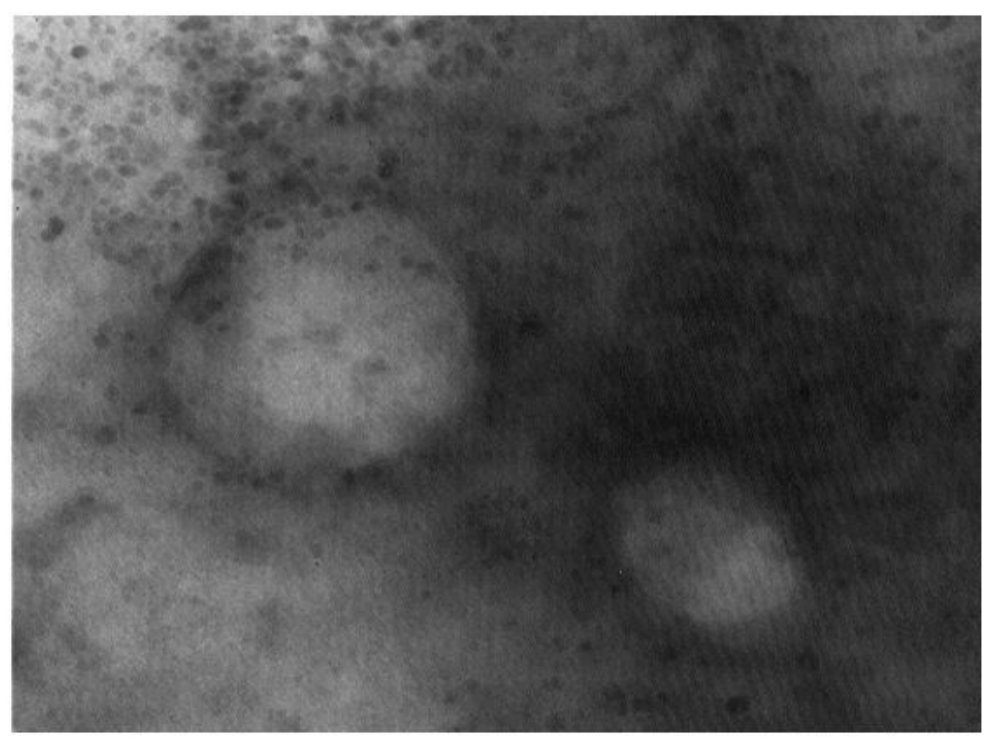

\section{Figure 5}

LSD nodules from infected Cattle: EEV form: The TEM, negative staining LSD viruses appears as a smooth bricks and the virus seems to have a full configuration that does not lack anything and has not been affected by any environmental conditions [NS-DEM 250000X]. 


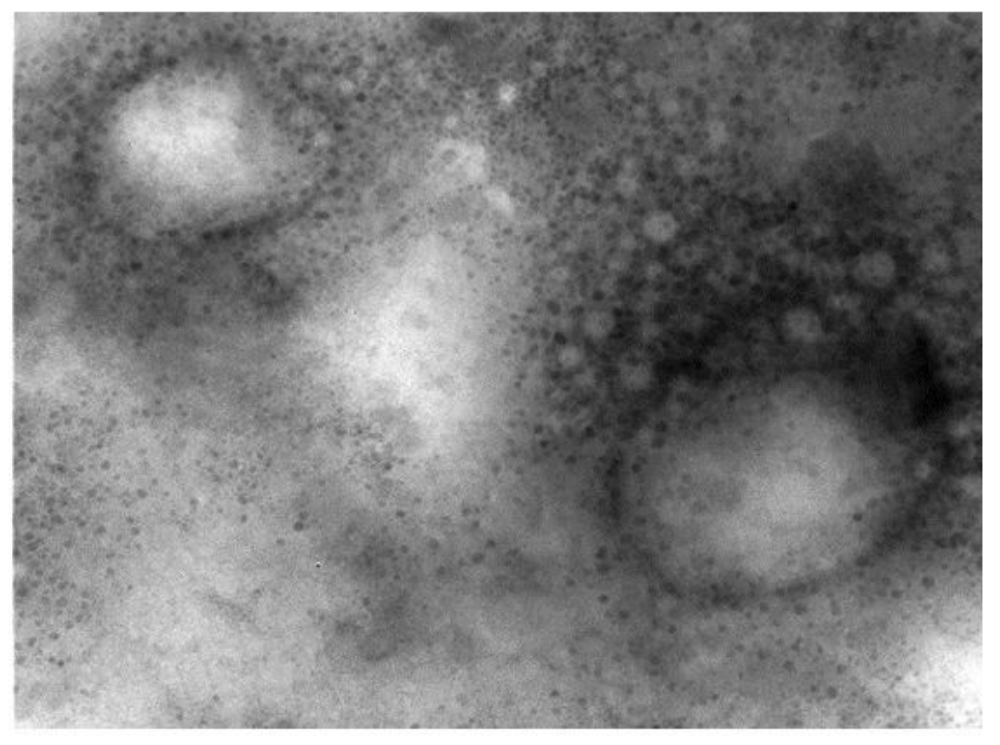

\section{Figure 6}

LSD nodules from infected Cattle: EEV form: The TEM, negative staining image showed herpes viruses surrounding the LSD virus and attached to its outer cover (envelope). Herpes viruses were collected in very large numbers and appeared in the adherent examination, although the test was performed on a solution, which means that the Herpes virus is well integrated with the LSD virus. The LSD virus appears as a smooth brick and the virus seems to have a full configuration that does not lack anything [NS-DEM 150000X].

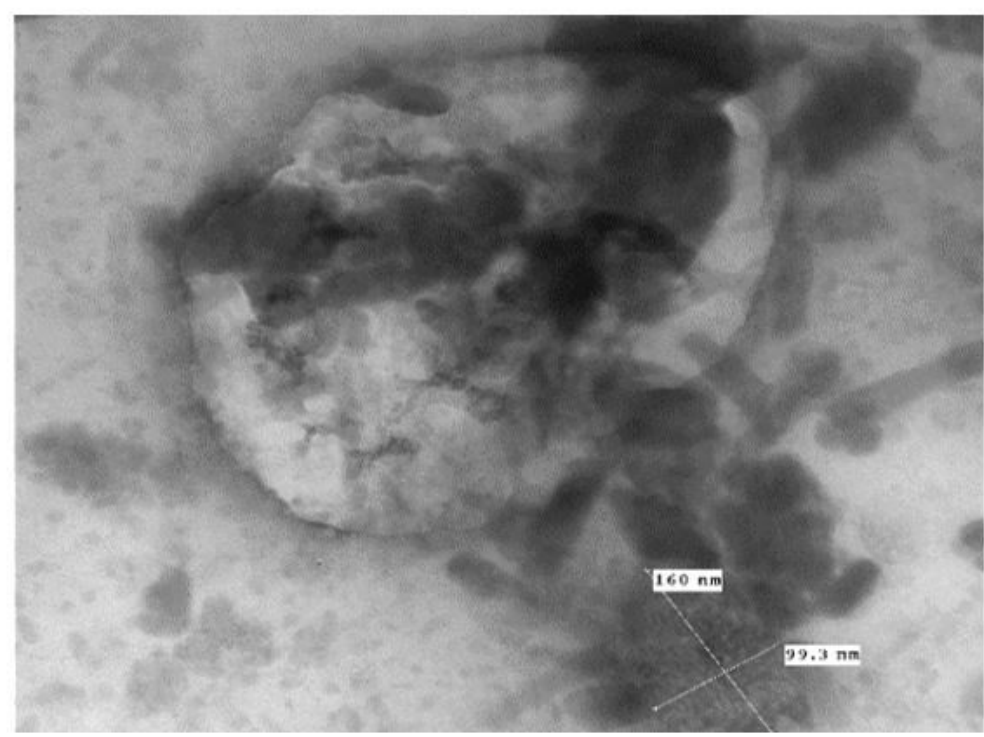

\section{Figure 7}

LSD nodules from infected Cattle: $M$ form: The TEM, negative staining image of the virus clearly \& covered with highly arranged structures in the form of overlapping short tubules of about (100 nm x $160 \mathrm{~nm})$ [NS-DEM 150000X]. 


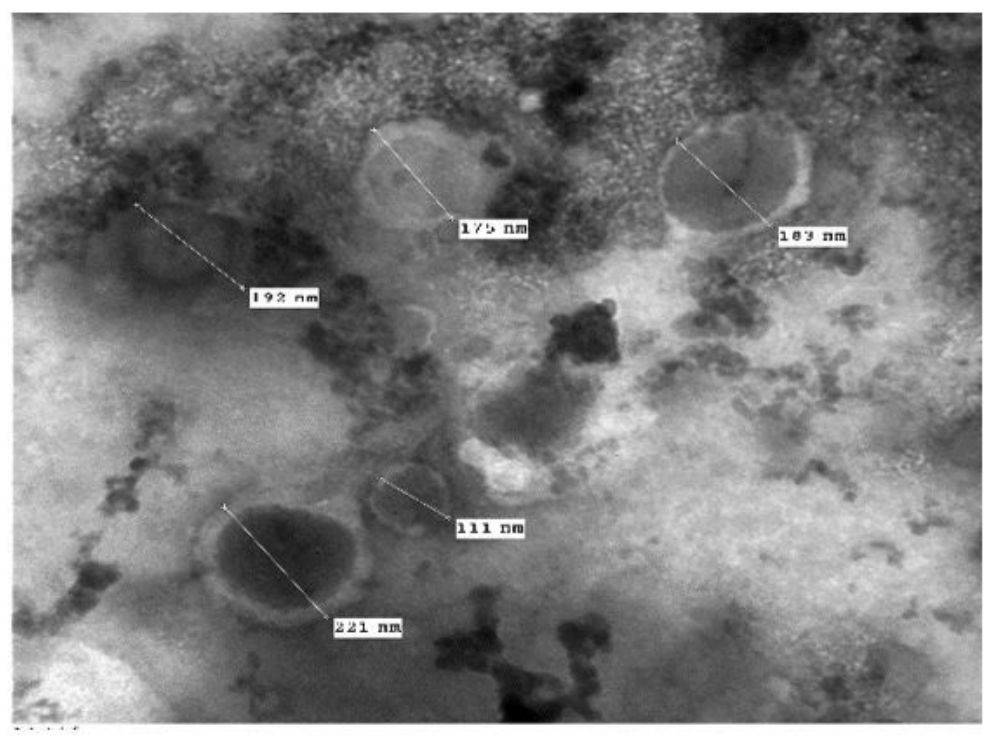

\section{Figure 8}

LSD nodules from infected Cattle: $M$ form: The TEM, negative staining picture shows a number of viruses partially covered by the internal viral membranes and surrounded by another incomplete membrane. Some viruses look relatively dark and surrounded by a light-colored membrane, It surrounded by a lightcolored membrane that may be composed of materials that do not absorb the dye. There is some relative variation in the size of viruses (111 $\mathrm{nm}-221 \mathrm{~nm}$ ), [NS-DEM 80000X].

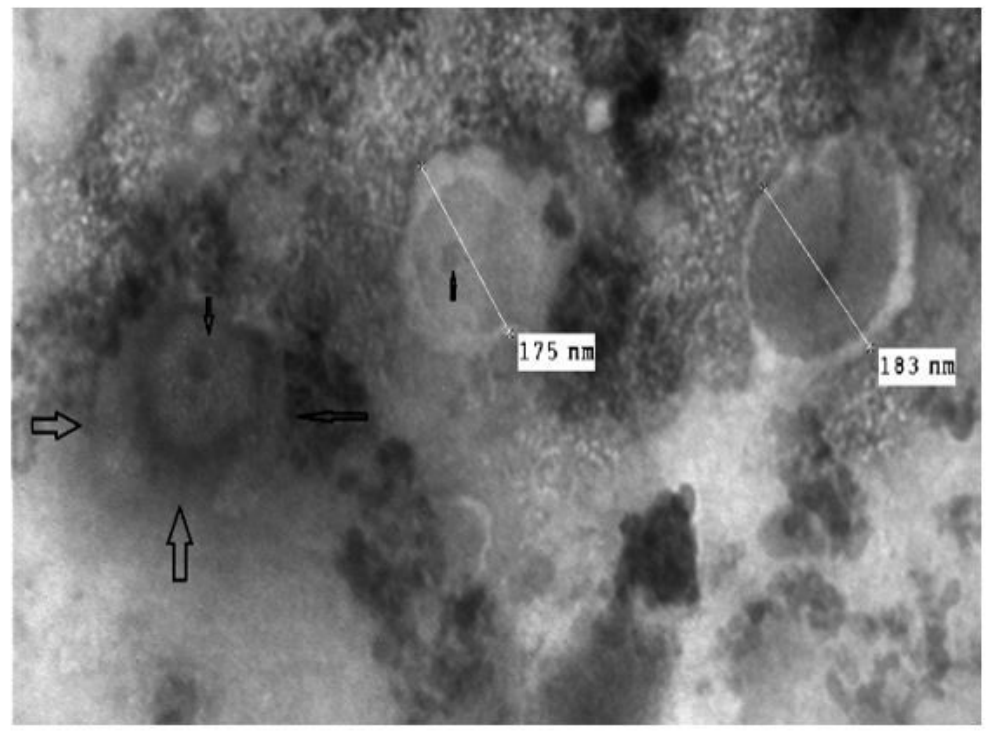

\section{Figure 9}

LSD nodules from infected Cattle: $M$ form: The TEM picture shows a number of viruses partially covered by the internal viral membranes and surrounded by another incomplete membrane. The picture shows well the internal structure of the virus and the exact cover consisting of short, intermittent tubes revolving around a center axis; it is surrounded by a thick, incomplete membrane, as if the virus is in the shape of a horseshoe (arrows) [NS-DEM 80000X]. 


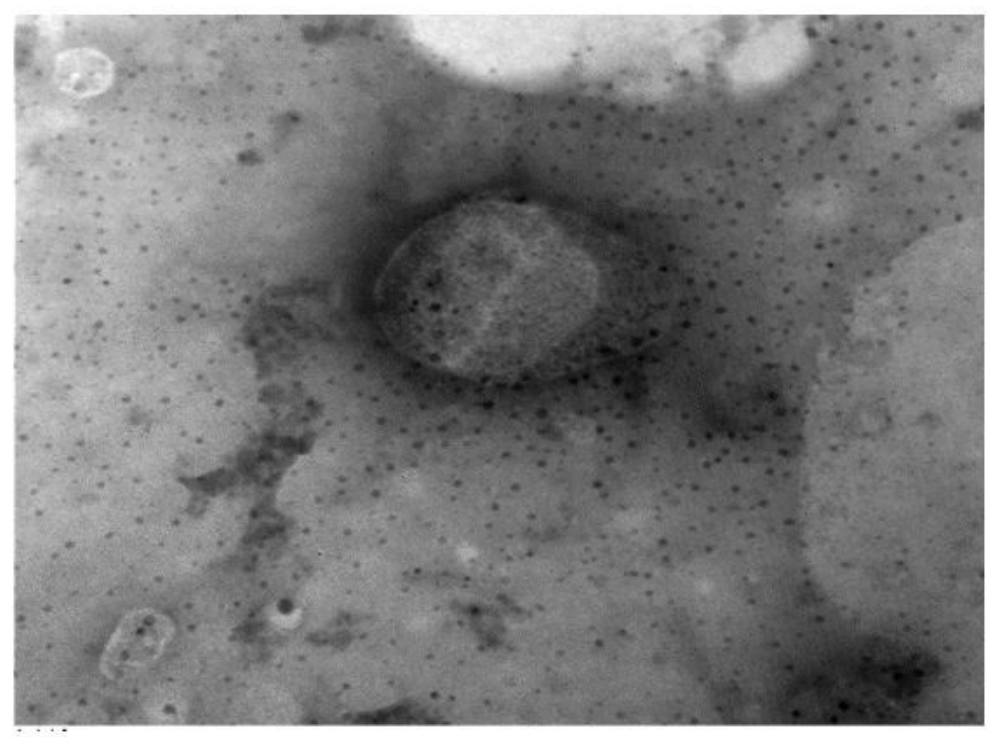

\section{Figure 10}

LSD nodules from infected Cattle: VV form: TEM, negative staining showing a virion component inside the virus appeared as cone shape. Half of the virus is exposed and the other side is funnel shape. The double stranded DNA molecule appears to be surrounded by a fine component that preserves it from the external environment [NS-DEM 100000X].

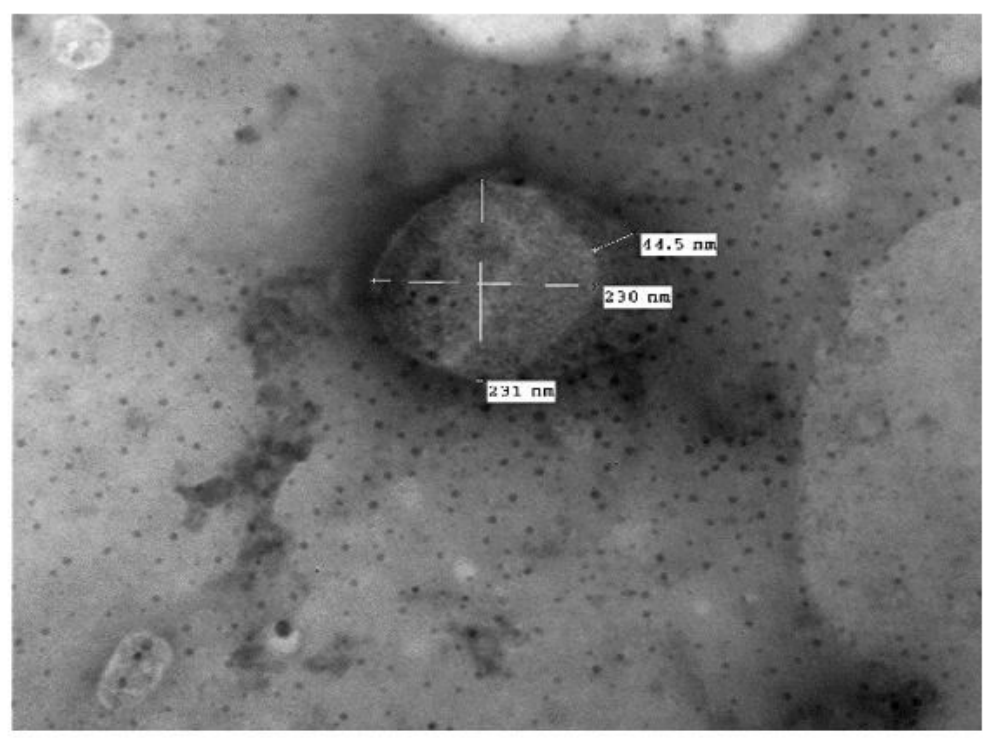

\section{Figure 11}

LSD nodules from infected Cattle: VV form: A virion showing a component inside the virus appeared cone-shaped. Half of the virus is exposed and the back is a funnel shape. The double stranded nucleic acid molecule appears to be surrounded by a fine component that preserves it from the external environment. Another part of the virion is covered by a smooth membrane which may be the incomplete envelope. This LSD virus virion is large, and about (230 $\mathrm{nm} \times 231$ $\mathrm{nm}$ ) [NS-DEM 100000X]. 


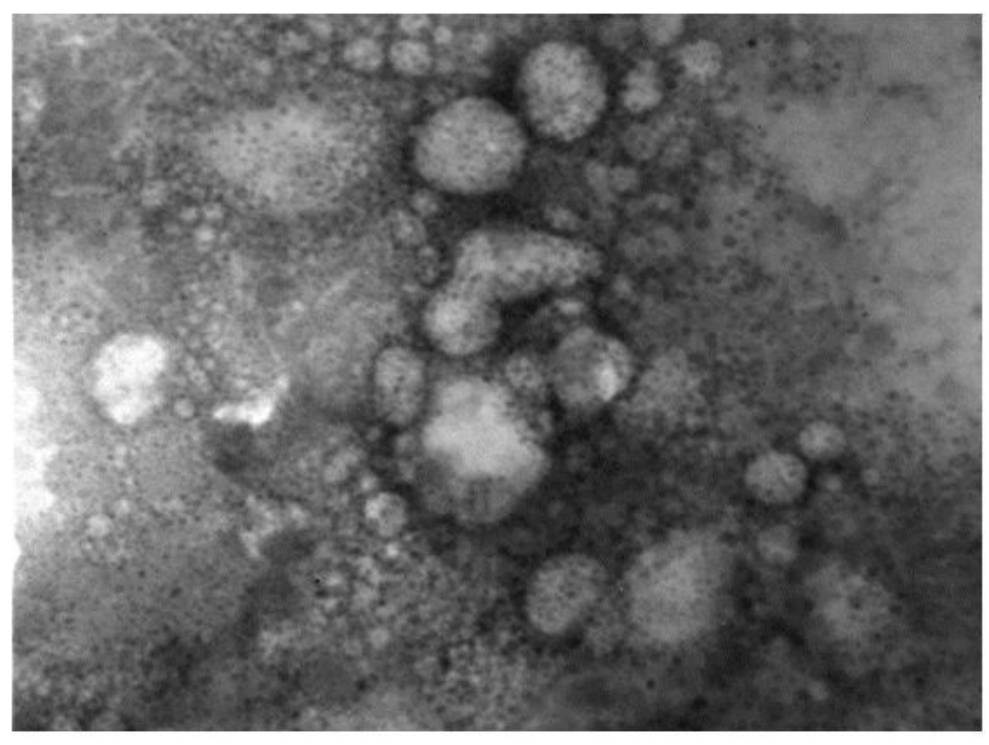

\section{Figure 12}

LSD nodules from infected Cattle: VV form: The TEM, negative staining image shows a group of viruses. The virus takes different pleomorphic forms. The membranes that retain viral components take an intermediate position among the enveloped and non-enveloped LSD viruses. This image showing herpes viruses interlaced with LSD viruses, and that viruses are virulent \& active [NS-DEM 120000X].

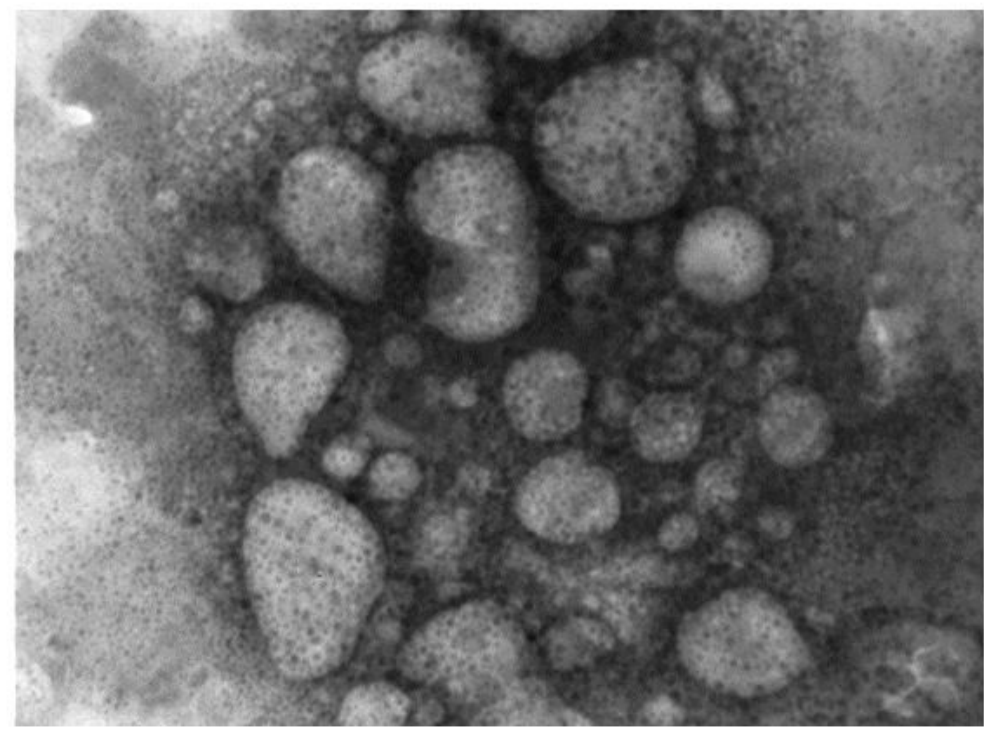

\section{Figure 13}

LSD nodules from infected Cattle: VV form: The TEM, negative staining image shows a set of interconnected viruses. The virus takes different pleomorphic forms. The membranes that retain viral components take an intermediate position among the enveloped and non-enveloped LSD viruses. The image shows herpes viruses interlaced with LSD viruses. The image gives the impression that viruses are very active [NS-DEM 120000X]. 


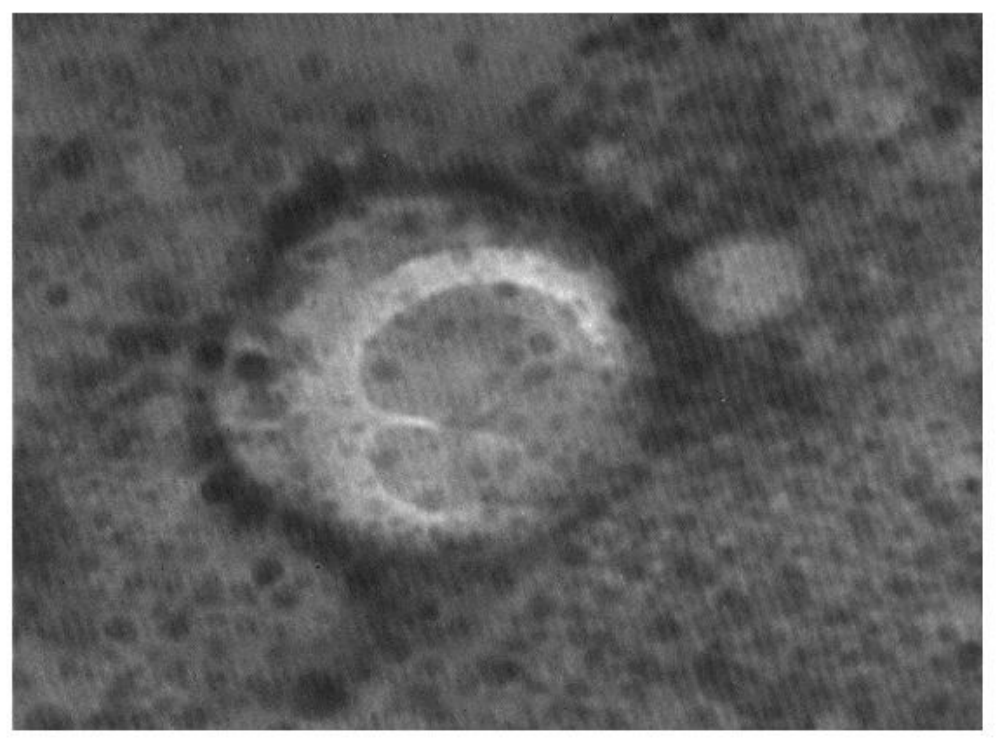

\section{Figure 14}

LSD nodules from infected Cattle: VV form: TEM, negative staining showing LSD virus surrounded by a transparent membrane showing the components it contains. This form of LSDV indicates virulence; it takes off its covers in preparation for new host. The image shows the herpes virus connected to a thin line extending towards the other virus and both viruses in a functional state [NS-DEM 200000X].

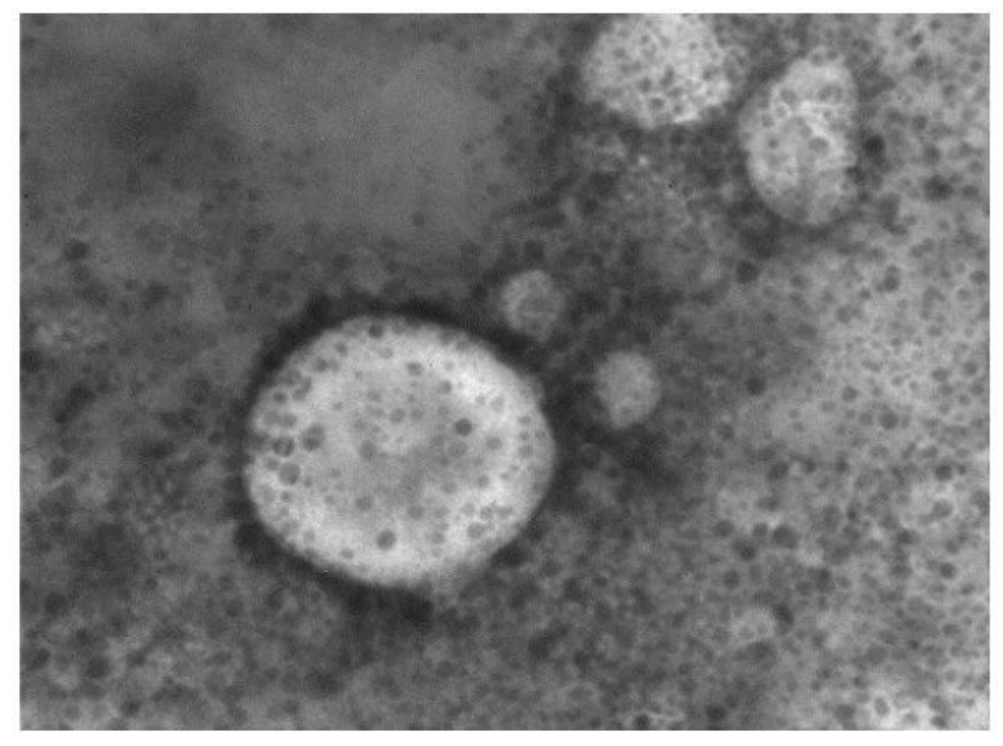

\section{Figure 15}

LSD nodules from infected Cattle: VV form; TEM, negative staining showing LSD virus surrounded by a transparent membrane showing the components it contains. The composition inside the virus appears to be quite similar to the nut- shells. Inside the figure shows a dark color while the frame that draws the shape is light colored. This form of LSDV indicates its virulence; it takes off its covers in preparation for new host [NS-DEM 200000X]. 


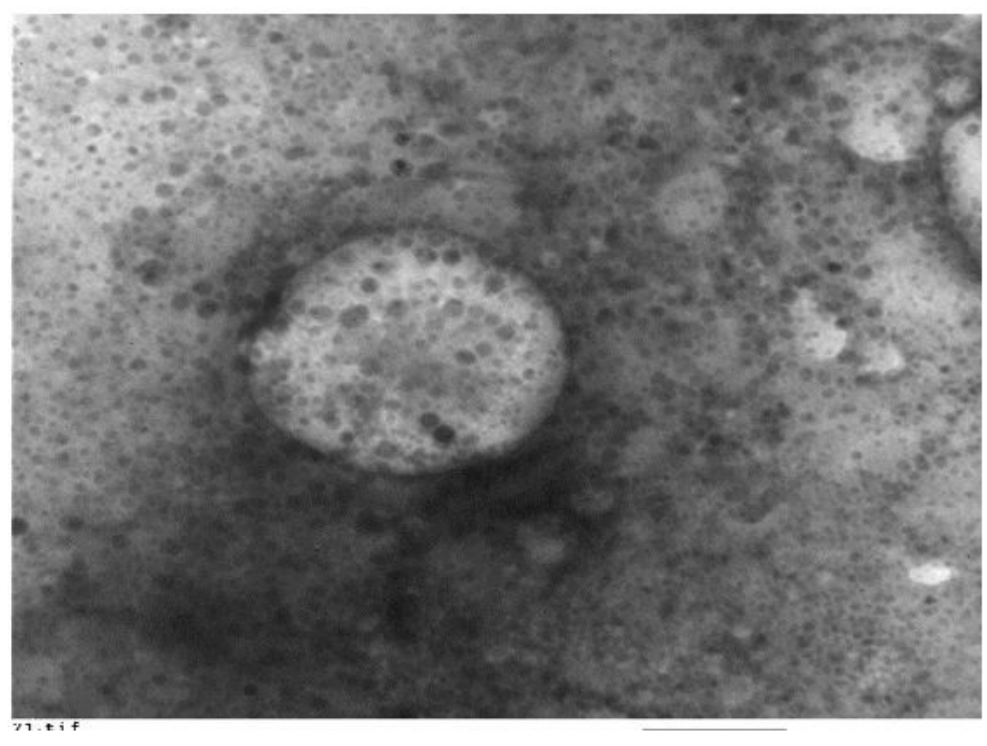

\section{Figure 16}

LSD nodules from infected Cattle: VV form; TEM, negative staining showing LSD virus surrounded by a transparent membrane showing the components it contains. The composition inside the virus appears to be quite similar to the nut- shells. Inside the figure shows a dark color while the frame that draws the shape is light colored. This form of LSDV indicates that it is very virulent; it takes off its covers in preparation for new host [NS-DEM 150000X].

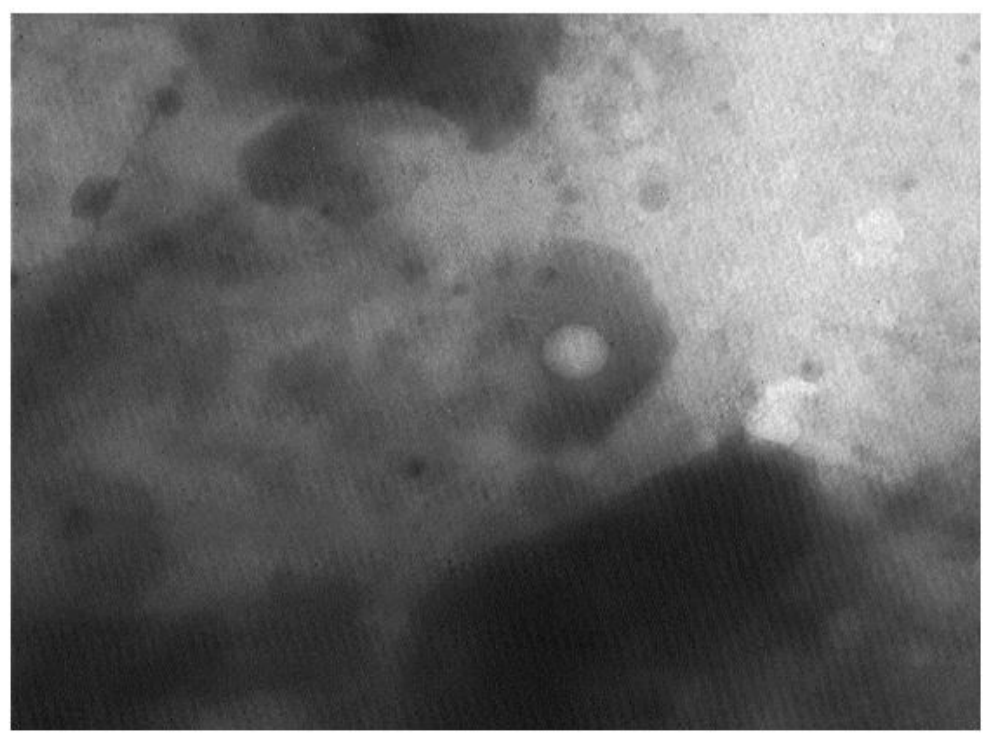

\section{Figure 17}

LSD nodules from infected Cattle: The Herpes virus. TEM, negative staining picture showing herpes virus as a tennis ball (core) in the middle of a halo (envelope), this is because the membranes surrounding it break easily to give this distinctive shape [NS-DEM 300000X]. 


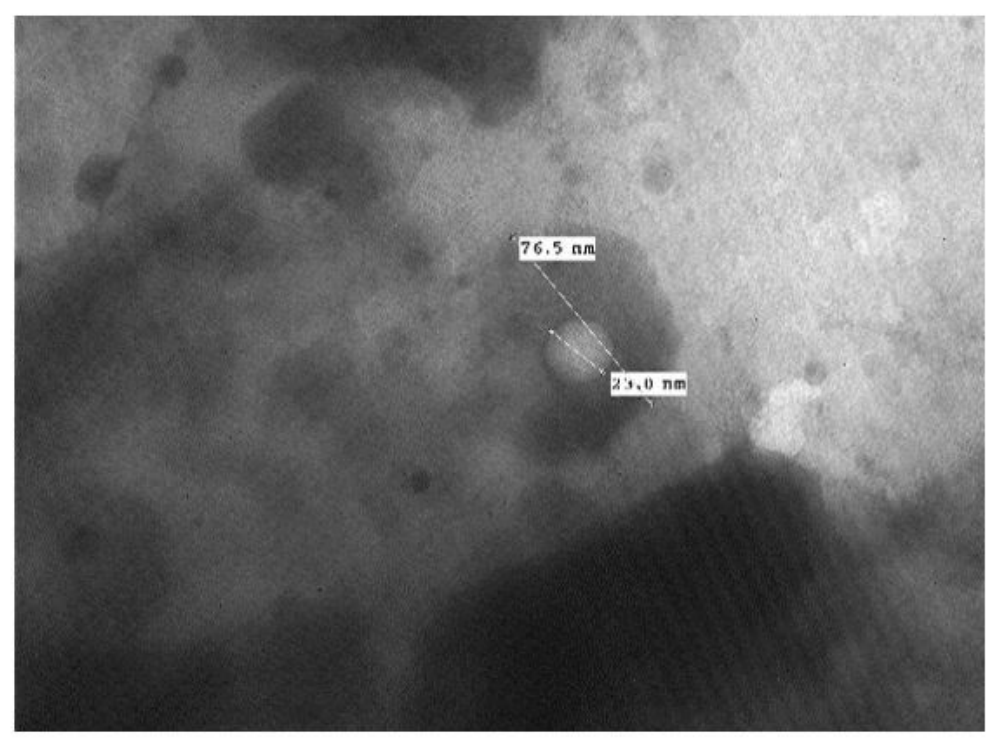

\section{Figure 18}

LSDV (Cattle): TEM, negative staining showing herpes virus in the shape of white ball (core) in the middle of a halo (envelope). This is because the membranes surrounding it break easily to give this distinctive shape and measuring about $23 \mathrm{~nm} \times 77 \mathrm{~nm}$ [NS-DEM 300000X].

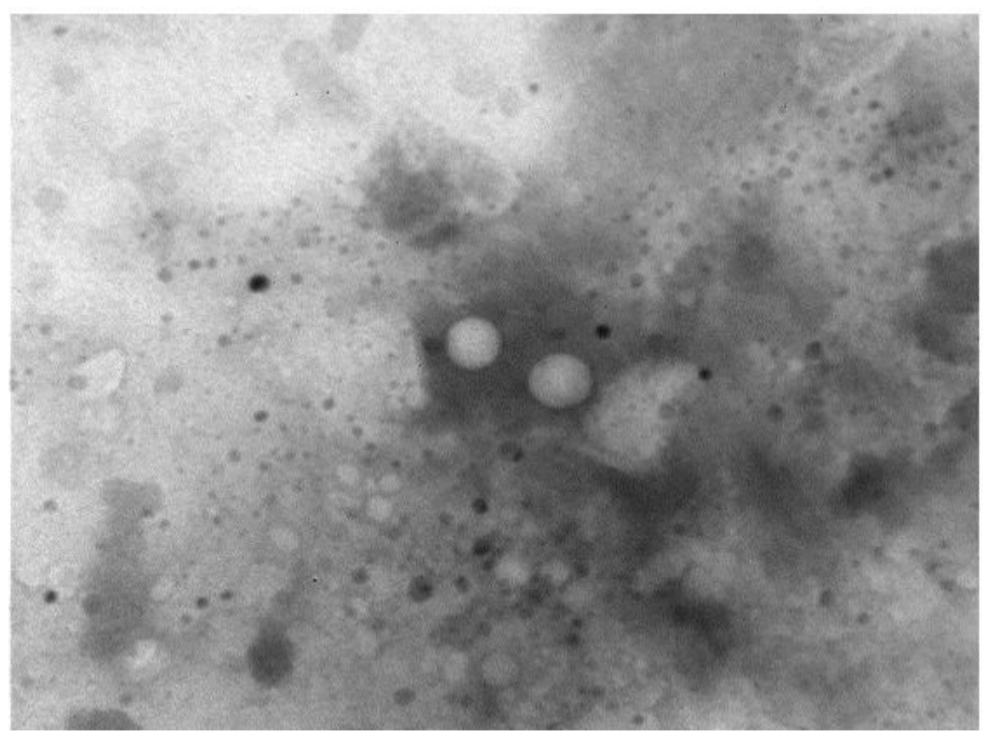

\section{Figure 19}

LSD nodules from infected Cattle: TEM, negative staining picture shows two herpes viruses as a tennis balls (cores) in the middle of a halo (envelope). This is because the membranes surrounding them break easily to give this distinctive shape [NS-DEM 200000X]. 


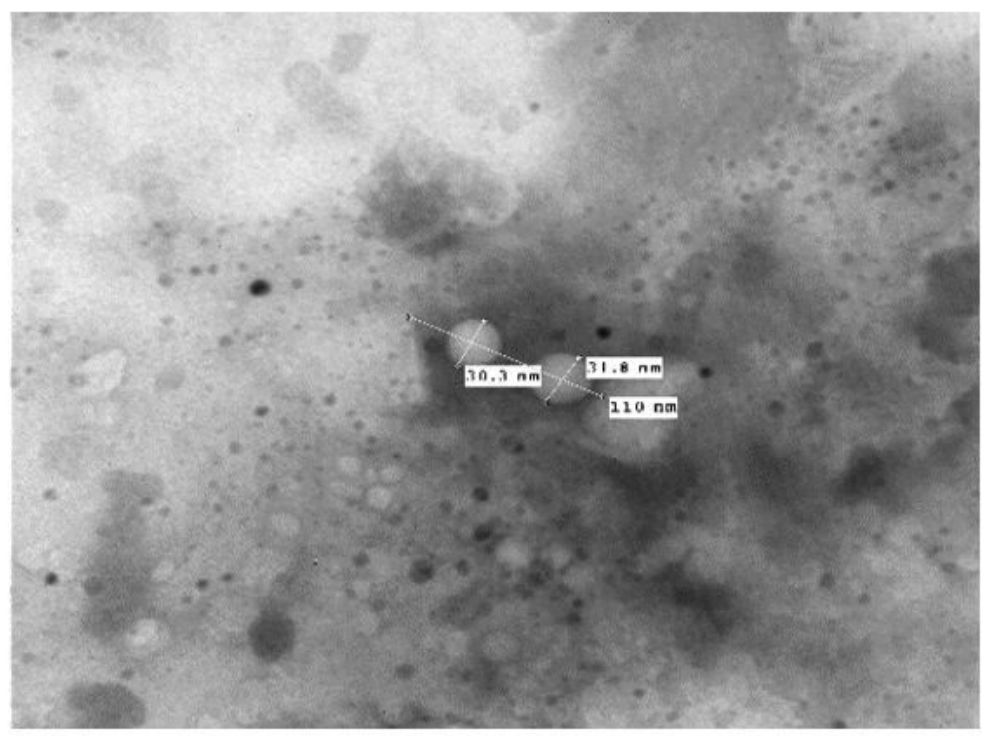

\section{Figure 20}

TEM, negative staining picture shows two herpes viruses as a tennis balls (cores) in the middle of a halo (envelope). This is because the membranes surrounding them break easily to give this distinctive shape [NS-DEM 200000X]

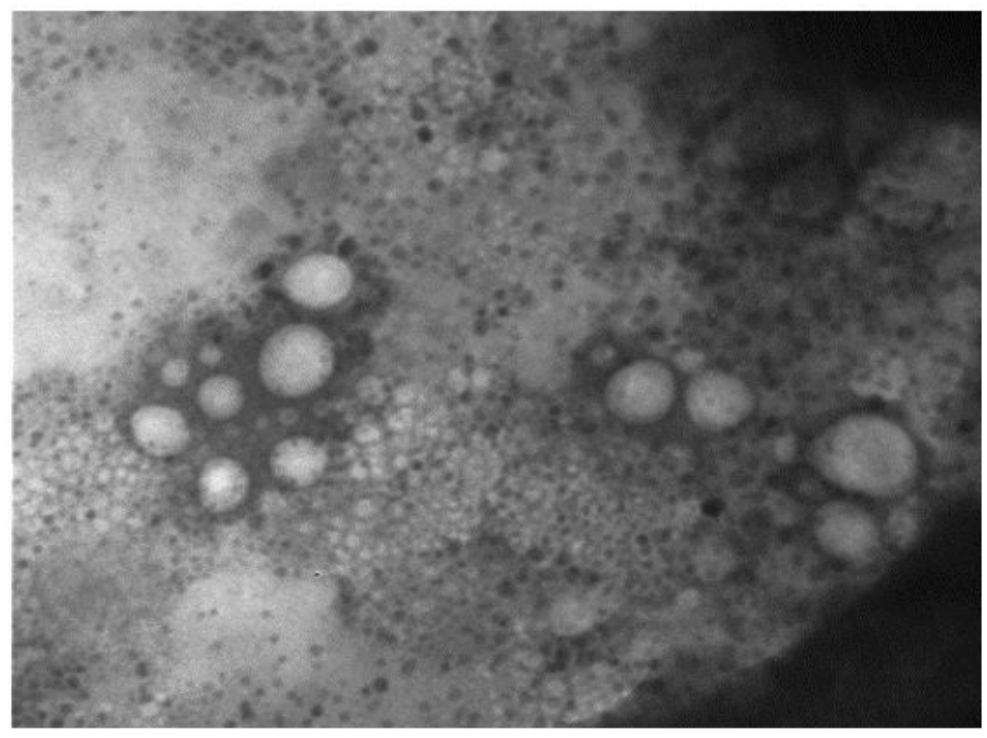

\section{Figure 21}

The TEM, negative staining picture shows herpes viruses in different sizes appear as a tennis balls (cores) in the middle of a halo (envelope). This is because the membranes surrounding them break easily to give this distinctive shape. The image shows herpes virus in large numbers and active state [NS-DEM 150000X].

\section{Figure 22}

The TEM, negative staining picture shows naked and enveloped herpes virus of aver- age sizes of $78.5 \mathrm{~nm}-81 \mathrm{~nm}$. The core of enveloped herpes virus measure about 33 nm. [NS-DEM 100000X]. 


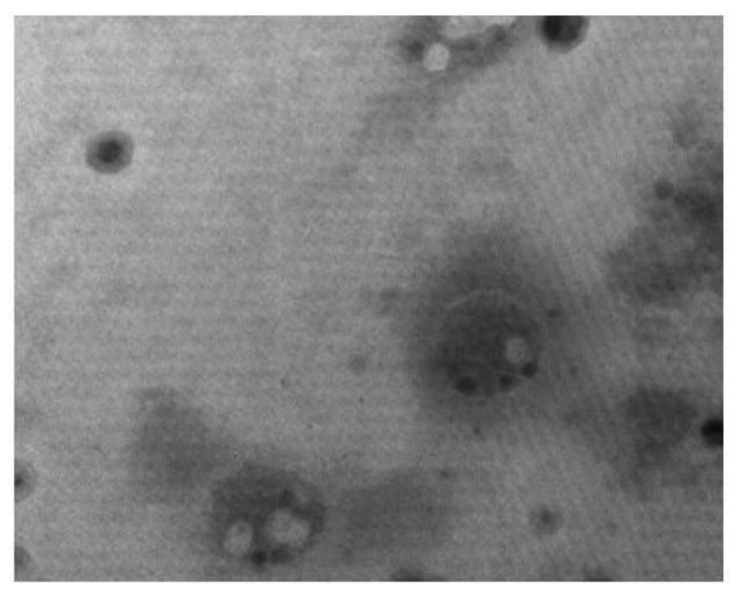

\section{Figure 23}

The TEM, negative staining image shows the enveloped Herpes virus, but the internal content appears because it is a weak membrane and breaks easily. Herpes viruses appear to be in a highly functional and in active state [NS-DEM 200000X].

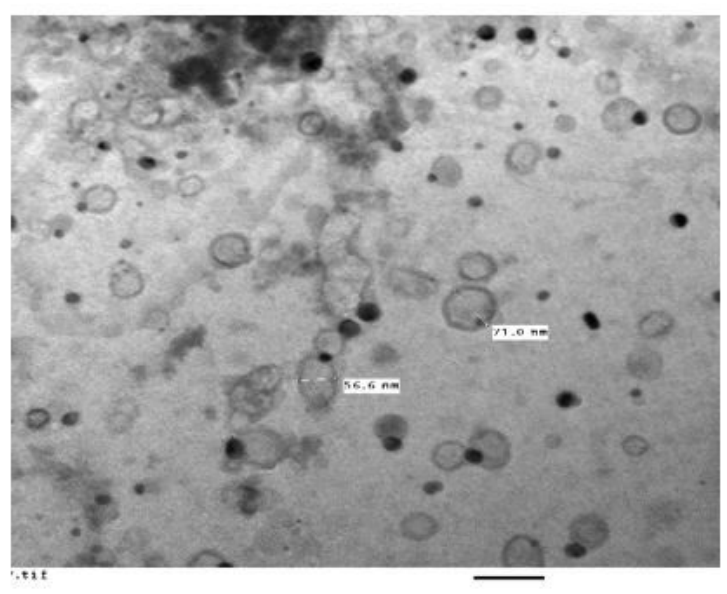

\section{Figure 24}

The TEM, negative staining picture shows naked herpes viruses of average sizes about $57 \mathrm{~nm}-72 \mathrm{~nm}$. The image shows herpes virus in large numbers and active [NS-DEM 100000X].

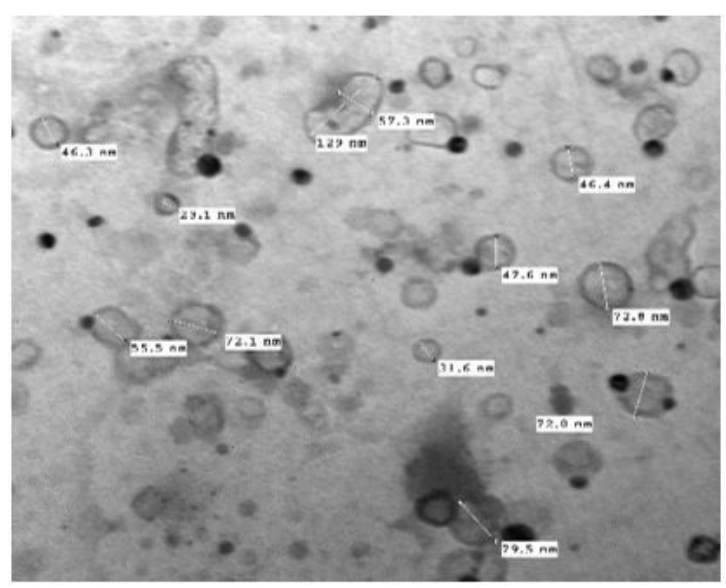

\section{Figure 25}

The TEM, negative staining picture shows naked herpes viruses of average sizes about $32 \mathrm{~nm}-80 \mathrm{~nm}$. The image shows herpes virus in large numbers and active [NS-DEM 100000X]. 


\section{Supplementary Files}

This is a list of supplementary files associated with this preprint. Click to download.

- Pictures.docx 